IdeAs

Idées d'Amériques

$2 \mid 2012$

Universités d'Amériques et construction des savoirs

\title{
The European University at a Crossroads
}

Boaventura de Sousa Santos

\section{(2) OpenEdition}

Journals

Édition électronique

URL : https://journals.openedition.org/ideas/276

DOI : 10.4000/ideas. 276

ISSN : 1950-5701

Éditeur

Institut des Amériques

Référence électronique

Boaventura de Sousa Santos, "The European University at a Crossroads », IdeAs [En ligne], 2 | 2012 mis en ligne le 25 juin 2012, consulté le 19 octobre 2022. URL : http://journals.openedition.org/ideas/ 276 ; DOI : https://doi.org/10.4000/ideas.276

Ce document a été généré automatiquement le 19 octobre 2022

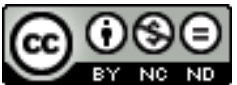

Creative Commons - Attribution - Pas d'Utilisation Commerciale - Pas de Modification 4.0 International - CC BY-NC-ND 4.0

https://creativecommons.org/licenses/by-nc-nd/4.0/ 


\title{
The European University at a Crossroads $^{1}$
}

\author{
Boaventura de Sousa Santos
}

1 When we consider the European university, or indeed the university worldwide, this is a moment in which it is as important to look back as to look forward. In the case of Europe, we are now right in the middle of the Bologna process. It is a period prone to intense fluctuations between positive and negative evaluations, between a sense that it is either too late or too early to achieve the results aimed at. In my view, such intense fluctuations in analysis and evaluation are a sign that everything remains open, that failure and success loom equally on the horizon, and that is up to us to make one or the other happen. The great philosopher Ernst Bloch wrote that by each hope there is always a coffin: Heil and Unheil. Though it is our main objective to focus on the European university it would be foolish not to think that the challenges facing the European university today are to be found in all continents, however different the reasons, the arguments, the proposed solutions may be.

2 In general we can assert that the university is undergoing - as much as the rest of contemporary societies - a period of paradigmatic transition. This transition can be characterized in the following way: we face modern problems for which there are no modern solutions. Very succinctly, our modern problems are the fulfilment of the ideals of the French Revolution: liberté, egalité, fraternité. In the past two hundred years we have not been able to fulfil such objectives in Europe, let alone elsewhere. The solutions designed to fulfil them have not been able to deliver the objectives so strenuously struggled for: I mean scientific and technological progress, formal and instrumental rationality, the modern bureaucratic state, the recognition of class, race and gender divisions and discriminations and the institutionalization of social conflict raised by them through democratic processes, development of national cultures and national identities, secularism and laicism, and so on. The modern university,

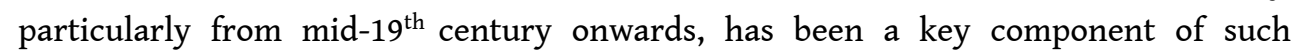
solutions. It was actually in light of them that institutional autonomy, academic freedom and social responsibility were originally designed. The generalized crisis of 
modern solutions has brought with it the crisis of the university. In the past forty years, for different but convergent reasons, in different parts of the world the university has become, rather than a solution for societal problems, an additional problem. After the Second World War, the early 1970s was a period of intense reformist impulses worldwide. In most cases, the student movements of the late 1960s early 1970s were the motive behind them.

3 The problem of the university may be formulated in this way: it is confronted with strong questions for which it has so far provided only weak answers. Strong questions are those questions that go to the roots of the historical identity and vocation of the university in order to question not so much the details of the future of the university but rather whether the university, as we know it, has indeed a future. They are, therefore, questions that arouse a particular kind of perplexity. Weak answers take the future of the university for granted.

4 The reforms they call for end up being an invitation to immobilism. They fail to abate the perplexity caused by the strong questions and may, in fact, even increase it. Indeed, they assume that the perplexity is pointless. I submit that we must take up the strong questions and transform the perplexity they cause into a positive energy both to deepen and reorient the reformist movement. The perplexity results from the fact that we are before an open field of contradictions in which there is an unfinished and unregulated competition among different possibilities. Such possibilities open space for political and institutional innovation by showing the magnitude of what is at stake.

\section{Eleven Strong Questions}

5 Let me give some examples of the strong questions facing the university at the beginning of the $21^{\text {st }}$ century. Without claiming to be exhaustive, I select eleven such questions. First strong question : given the fact that the university was part and parcel of the building of the modern nation-state - by training its elites and bureaucracy, by providing the knowledge and ideology underlying the national project - how is the mission of the university to be refounded in a globalized world, a world in which state sovereignty is increasingly shared sovereignty or simply a choice among different kinds of interdependence, and in which the very idea of a national project has become an obstacle to dominant conceptions of global development? Is the global university a possible answer? In which case, how many such global universities are viable? What happens to the large number of the remaining ones? If global elites are to be trained in global universities, where to find in society the allies and the social base for the nonglobal universities? What kinds of relationships between global and nonglobal universities will there be? Will the focus on ranking contribute to the cohesion of the European higher education area or, on the contrary, to its segmentation through unfair competition and the rise of commercial internationalism?

6 A second strong question may be formulated as follows: The idea of a knowledge society implies that knowledge is everywhere; what is the impact of this idea on a modern university which was created on the premise that it was an island of knowledge in a society of ignorance? What is the place or the specificity of the university as a center of knowledge production and diffusion in a society with many other centers of production and diffusion of knowledge? 
7 Third strong question: At its best, the modern university has been a locus of free and independent thinking and of celebration of diversity, even if subjected to the narrow boundaries of the disciplines, whether in the sciences or the humanities. Bearing in mind that for the past 30 years the tendency to transform the truth value of knowledge into the market truth value of knowledge has become increasingly strong, could there be any future for nonconformist, critical, heterodox, non-marketable knowledge, and for professors, researchers and students pursuing it? If yes, what will be its impact upon the criteria of excellence and inter-university competitiveness? If not, can we still call university an institution that only produces competent conformists and never competent rebels, and that only regards knowledge as a commodity and never as a public good?

8 Fourth strong question: The modern university has been from the beginning a transnational institution at the service of national societies. At its best, the modern university is an early model for international flows of ideas, teachers, students and books. We live in a globalized world but not in a homogeneously globalized world. Not only are there different logics moving globalized flows but also different power relations behind the distribution of the costs and benefits of globalization. There is transnational greed as there is transnational solidarity. Which side will the university be on? Will it become a transnational corporation or a transnational cooperative or non-profit organization? Is there a contradiction between our emphasis on cultural and social development and the emphasis of some European politicians and powerful thinktanks on economic development and the university's contribution to the global competitiveness of European businesses? Why have some major reform efforts outside Europe chosen the slogan: "Neither Bologna nor Harvard"?

9 Fifth strong question: In the long run, the idea of Europe is only sustainable as the Europe of ideas. Now, the university has historically been one of the main pillars of the Europe of ideas, however questionable such ideas may have been. This has been possible by granting to the university a degree of institutional autonomy unimaginable in any other state institution. The dark side of this autonomy has been social isolationism, lack of transparency, organizational inefficiency, social prestige disconnected from scholarly achievement. In its original design, the Bologna process was to put an end to this dark side without significantly affecting the university's autonomy. Is this design being carried out without perverse results? Is the Bologna process a break with the negative aspects of the traditional university, or is it a brilliant exercise in reshuffling inertias and recycling old vices? Is it possible to standardize procedures and criteria across such different university cultures without killing diversity and innovation? Is it possible to develop transparency, mobility and reciprocal recognition while preserving institutional and cultural diversity? Why are bureaucrats taking control of the good ideas and noble ideals so easily?

10 Sixth strong question: Job prestige goes together with job qualification and scarcity. The modern university has been at the core of the social production of high-powered job qualifications. If rankings manage to fragment the European and the future global university system, which jobs and which qualifications will be generated by which universities? The world system is built on an integrated hierarchy of core, peripheral and semi-peripheral countries. The current financial and economic crisis has shown that the same hierarchy holds in Europe and, as such, social cohesion is showing its dark side: it exists on the condition that the structural hierarchy not be affected, that 
countries remain as core, peripheral or semiperipheral, without moving either up or down in the hierarchy. Not necessarily coincident with location in the hierarchy of the countries in which they are located are we going to have peripheral, semi-peripheral and central universities? Will the Bologna process rigidify such hierarchies or make them more liquid? Depending on the geopolitical distribution of rankings, will hierarchy among universities contribute to the accentuating or rather to the attenuating of the hierarchies among European countries?

11 Seventh strong question: As the university diversifies the degrees of qualification first, second, third cycle and postdoctoral degrees - social illiteracy increases in the lower degrees, thus justifying the greater value of higher degrees. This is in fact a spiral movement. Has it exhausted its development potential? How many more cycles are we going to have in the future? Are we creating endless illiteracy in the same process that we create endless knowledge? Will peripheral and semi-peripheral universities be charged with solving the illiteracy problem, while the core universities will have the monopoly of highly qualified knowledge?

12 Eighth strong question: Can the university retain its specificity and relative autonomy while being governed by market imperatives and employment demands? Given the highly problematic validity of cost-benefit analysis in the field of research and development, will the university be allowed to assume certain costs in the expectation of uncertain benefits, as it has always done in the past? What will happen to knowledge that has not and should not have market value? Regarding marketable knowledge which impact on it is to be expected if such knowledge is going to be valued exclusively according to its market value? What is the future of social responsibility if extension is reduced to an expedient or burden to raise financial resources? What will happen to the imperative of making the university relevant to the needs of society, taking for granted that such needs are not reducible to market needs and may actually contradict them?

Ninth strong question: The university (or at least the public university) has historically been embedded in the three pillars of modern social regulation - the state, the market and civil society; however, the balance of their presence in the structure and functioning of the university has varied in the course of time. Indeed, the modern European university started here in Bologna as a civil society initiative. Later on, the state strengthened its presence which became dominant from mid- $19^{\text {th }}$ century onwards, and in the colonies particularly after they became independent. In the last 30 years the market took the lead in structuring the university life. In a few decades the university went from producing knowledge and professionals for the market, to becoming itself a market, the market of tertiary education, and finally, at least according to powerful visionaries, to being run like a market organization, a business organization. Since then, civil society concerns have been easily confused with market imperatives or subordinated to them, and the state has very often used its coercive power to impose market imperatives to the reluctant universities. Is the Bologna process a creative response to neoliberal, one-dimensional demands or, on the contrary, a way of imposing them through a transnational European process that neutralizes national resistance?

14 Tenth strong question: The European universities and many other universities around the world that followed their model were instrumental in disseminating a Eurocentric view of the world, a view powerful enough (in both intellectual and military terms) to 
claim universal validity. This claim did not involve ignoring the cultural, social and spiritual differences of the non-European world. On the contrary, it entailed knowing such differences, even though subjected to Eurocentric purposes, whether the romantic celebration of the Other or the colonial subjugation and destruction of the Other. In both cases, knowing the Other was at the service of showing the superiority and therefore the universality of European culture; a detailed, colonial or imperial knowledge of the Other was required. My university, for instance, the University of Coimbra, founded in 1290, contributed immensely to the development of knowledge committed to the colonial enterprise. The quality and intensity of the homework done by the missionaries before embarking overseas is astounding, all the more astounding when we compare it with the homework done by WB and IMF executives when they go around evangelizing the world with the neoliberal orthodoxy in their heads and pockets. Of their knowledge claims it cannot be said what the great leader of the African Liberation movements, Amilcar Cabral, said about colonial knowledge : "The search for such knowledge, in spite of its unilateral, subjective and very often unfair character, does contribute to enriching the human and social sciences in general" (Cabral, 1978b : 314, my translation).

The tenth question is this: Is the university prepared to recognize that the understanding of the world by far exceeds the western understanding of the world? Is the university prepared to refound the idea of universalism on a new, intercultural basis? We live in a world of norms in conflict and many of them are resulting in war and violence. Cultural differences, new and old collective identities, antagonistic political, religious and moral conceptions and convictions are today more visible than ever, both outside and inside Europe. There is no alternative to violence other than readiness to accept the incompleteness of all cultures and identities, including our own, arduous negotiation, and credible intercultural dialogue. If Europe, against its own past, is to become a beacon of peace, respect for diversity and intercultural dialogue, the university will certainly have a central role to play. Are the European universities being reformed having such role in mind as a strategic objective of their future?

The eleventh question, probably the strongest of them all, is the following: Modern universities have been both a product and a producer of specific models of development. When the Bologna process started there were more certainties about the European project of development than there are today. The compound effect of multiple crises - the financial and economic crisis, the environmental and energetic crisis, the crisis of the European social model, the migration crisis, the security crisis points to a civilizatory crisis or paradigmatic change. The question is: In such a tumultuous time, is the university's serenity possible? And, if possible, is it desirable? Is the Bologna process equipping the university to enter the debate on models of development and civilizatory paradigms, or rather to serve as acritically and as efficiently as possible the dominant model decided by the powers that be and evaluated by the new supervisors of the university output at their service? At the international level, given the conflict between local conceptions of autonomous development and the global development model imposed by the rules of the WTO, and given the fact that the European states are donor states, will the European university contribute to a dialogue among different models of development? Or will it rather provide intellectual legitimacy to unilateral impositions by the donor states, as in the colonial period? 


\section{Two Future Visions and a Choice} providing only weak answers to these strong questions. The weakest of them all are the nonanswers, the silences, the taken-for-grantedness of the new common sense about the mission of the university. This is a situation that we should overcome as soon as possible. The danger is to convert really mediocre achievements into brilliant leaps forward, to disguise resignation behind the mask of consensus, to orient the university towards a future in which there is no future for the university. To my mind, we are at a juncture which our complexity scientists would characterize as a situation of bifurcation. Minimal movements in one or other direction may produce major and irreversible changes. Such is the magnitude of our responsibility. We all know that we never act upon the future; we act upon the present in light of our anticipations or visions of how the future will look like. The strong questions indicate that there is no single, consensual anticipation or vision to be taken for granted, and that is why the questions invite deep reflection. I suggest that we are before two alternative visions and that their co-presence is the source of the tensions running through our university system today. They both invite two opposing imaginary visions of a retrospective evaluation of the reforms under way. That is, they look from the future at our present. According to one of them, our reform efforts were indeed a true reform, as they succeeded in preparing the university to confront the challenges of the $21^{\text {st }}$ century effectively - by diversifying its mission without giving away its authenticity, by strengthening institutional autonomy, academic freedom and social responsibility under the new and very complex conditions of Europe and of the world at large. Thus, the European university was able to rebuild its humanistic ideal in a new internationalist, solidary and intercultural way. According to the other, imaginary, retrospective vision, the Bologna process was, on the contrary, a counterreformation, as it blocked the reforms that the universities in different European countries were undertaking individually, and each one according to its specific conditions to face the above-mentioned challenges; furthermore, the Bologna process forced a convergence beyond a reasonable level. It did this with the purpose of disabling the university from the mechanisms that would allow it to resist against the business and market imperatives in the same manner as it resisted in the past against the imperatives of religion and later of the state.

In order not to end this talk on a pessimistic note, I will start by briefly detailing the second retrospective vision and then turning to the first one. The second vision, the vision of the counterreformation, displays before us a dystopic scenario with the following features.

19 As we realize that the financial crisis has unveiled the dangers of creating a single currency without putting together public and fiscal policies and state budgets, it may well happen that, in the long run, the Bologna Process turn out to be the euro of European universities. Here are the foreseeable consequences: the principles of solidary university internationalism and respect for cultural diversity will be discarded in the name of the efficiency of the European university market and competition; the weaker universities (gathered in the weaker countries) will be dumped by the university rating agencies into the ranking garbage bin. Though claiming to be rigorous, university ranking will be, in a great measure, arbitrary and subjective. Most 
universities will suffer the consequences of fast decrease of public funding; many universities will be forced to close down. As is happening in other levels of education, the wealthy students and their parents will search throughout many countries for the best quality/price ratio, as they are already doing in the commercial malls which universities are also becoming, while the poor students and their parents will be confined to the poor universities existing in their poor countries or neighbourhoods. The internal impact will be overwhelming: the relation between research and teaching, highly advertised by Bologna, will be a very paradise for the universities at the top of the ranking (a scarce minority) and perfect hell for the large majority of the universities and their scholars. The commodification criteria will reduce the value of the different areas of knowledge to their market price. Latin, poetry or philosophy will be kept only if some informatic McDonald recognizes in them any measure of usefulness. University administrators will be the first ones to internalize the classifying orgy, an orgy of objective maniacs and indicators maniacs; they will excel in creating income by expropriating the students' families or robbing the faculty of their personal lives and leisure. They will exert all their creativity to destroy university creativity and diversity, to standardize all that is standardizeable and to discredit or discard all that is not. The faculty will be proletarianized by the very means of educational production of which they are supposedly owners - that is, teaching, assessment, research. They will end up being zombies of forms, objectives, evaluations that are impeccable in terms of formal rigor but necessarily fraudulent in substance - workpackages, deliverables, milestones, mutual citation deals to improve the indices, evaluations of where-youpublish-but-what-I-couldn't-care-less, careers conceived as exhilarating but flattened at the low positions in most situations. For the younger faculty the academic freedom will be a cruel joke. The students will be as masters of their learning as they will be slaves of their indebtedness for the rest of their lives. They will enjoy autonomy and free choice in curricular matters with no idea of the logic and limits of the choices presented to them, and will be guided, in personalized fashion, toward a mass alternative of professional employment or of professional unemployment. Tertiary education will be finally liberalized according to the rules of the World Trade Organization.

As I said, none of the above has to happen. There is another retrospective vision, and in our hearts and minds we very much hope that it will prevail. But for it to happen, we should start by recognizing and denouncing that the supposed new normalcy of the state of affairs in the above description is in fact a moral aberration and will entail the end of the university as we know it. Let us consider now the other retrospective vision, the vision which, looking from the future into our present, evaluates the Bologna process as a true reform that changed the European university deeply and for the better. Such vision will emphasize the following features of our current undertakings.

First, the Bologna process was able to identify and solve most of the problems that the pre-Bologna university was suffering and unable to confront, such as: established inertias that paralysed any reformist effort; endogamic preferences that created aversion to innovation and challenge; institutional authoritarianism under the guise of scholarly authority; nepotism under the guise of merit; elitism under the guise of excellence; political control under the guise of democratic participation; neo-feudalism under the guise of department or school autonomy; fear of being evaluated under the guise of academic freedom; low scientific production justified as heroic resistance to 
stupid terms of reference or comments by referees; generalized administrative inefficiency under the guise of respect for tradition.

Second, in so doing the Bologna process, rather than discrediting and throwing overboard the self-evaluation and reformist efforts that were being undertaken by the most dedicated and innovative professors and administrators, provided them with a new framework and powerful institutional support, to the extent that the Bologna process could become an endogenous energy rather than an outside imposition. In order to succeed in this, the Bologna process managed to combine convergence with diversity and difference, and developed mechanisms of positive discrimination to allow for the different national university systems to cooperate and compete among themselves in fair terms.

Third, the Bologna process never let itself be taken over by the so-called international tertiary education experts with the capacity of transforming subjective, arbitrary preferences into self-evident truths and inevitable public policies. It kept in sight two powerful intellectual views of the mission of the university produced in the early years of the past century and unequivocally took sides between the two. One was formulated by Ortega y Gasset and Bertrand Russell, two intellectuals with very different political ideas, but who converged in denouncing the political instrumentalization of the university; the other, formulated by Martin Heidegger in his inaugural lecture as rector of Freiburg university in 1933, in which he invited the university to contribute to the preservation of the German strengths of soil and blood. The Bologna process unequivocally adopted the first and refused the second.

Fourth, the reformists never confused the market with civil society or the community and urged the universities to keep a broad conception of social responsibility, encouraging action research as well as extension projects aimed at bettering the lives of the more vulnerable social groups trapped in systemic social inequality and discrimination, be they women, the unemployed, young and elderly people, migrant workers, ethnic and religious minorities, and so on.

Fifth, the reform process made it very clear that the universities are centers of production of knowledge in the broadest possible sense. Accordingly, it promoted interculturality, heterodoxy and critical engagement in the best liberal tradition which the pre-Bologna university had abandoned in the name of political or economic correctness. In the same vein, it encouraged internal scientific pluralism and, most importantly, granted equal dignity and importance to knowledge with market value and knowledge with no possible market value. Moreover, the reformists understood clearly all along that in the field of research and development, cost-benefit analysis is a very crude instrument and may kill innovation instead of promoting it. In fact, the history of technology amply shows that the innovations with highest instrumental value were made possible with no attention to cost/benefit calculations.

Sixth, the Bologna process managed to strengthen the relationship between teaching and research, and, while rewarding excellence, it made sure that the community of university teachers would not be divided between two stratified segments: a small group of first class university citizens with abundant money, light teaching loads and other good conditions to carry out research, on the one hand, and, on the other, a large group of second class university citizens enslaved by long hours of teaching and tutoring with little access to research funds only because they were employed by the wrong universities or were interested in supposedly wrong topics. It managed to 
combine higher selectivity in recruitment and strict accountability in the use of teaching time and research funds with a concern for really equal opportunities. It conceived of the rankings as the salt in food: too little makes it unpalatable; too much kills all the flavors. Moreover, at a given point it decided that what had happened in international rankings elsewhere could be applied to the university system as well. Accordingly, as the GDP index exists today side by side with the index of human development of the UNDP, the Bologna process managed to insert internal plurality in the ranking systems.

Seventh, the Bologna process ended up abandoning the once fashionable concept of human capital after concluding that the universities should form full human beings and full citizens and not just human capital subjected to market fluctuations like any other capital. This had a decisive impact on the curricula and on the evaluation of performances. Furthermore, the Bologna process managed to convince the European Union and the European states that they should be financially more generous with the public universities not because of corporatist pressures but rather because the investment in an excellent public university system is probably the best way of investing in the future of a Europe of ideas, the only way for Europe to remain truly European.

Finally, the Bologna process expanded exponentially the internationalization of the European university but took good care to promote other forms of internationalism than commercial internationalism. In this way, the European area of higher education ceased to be a threat to the academic freedom and intellectual autonomy of universities throughout the world to become a loyal and powerful ally in keeping the ideas of academic freedom, institutional autonomy and knowledge diversity well and alive in a world threatened by the pensée unique of market imperatives.

I have presented you with two alternative visions of our future. There is no doubt in my mind that all of us here wish that our future be molded by the second retrospective vision I just described. It is in our hands to make that happen.

\section{NOTES}

1. Keynote address delivered at the meeting on the occasion of the XXII Anniversary of the Magna Charta Universitatum, held at the University of Bologna, on September 16, 2010. 


\section{AUTEUR}

\section{BOAVENTURA DE SOUSA SANTOS}

Professor at the University of Coimbra. Distinguished Legal Scholar of the University of MadisonWisconsin, Global Legal Scholar of the University of Warwick. 